\title{
Antibacterial wound dressing nanofibrous mats composed of cellulose acetate loaded with chitosan/erythromycin nanoparticles
}

\section{Maryam Doostan}

Kermanshah University of Medical Sciences

Hassan Maleki

Kermanshah University of Medical Sciences

Mahtab Doostan

Tehran University of Medical Sciences

Kamyar Khoshnevisan

Tehran University of Medical Sciences

Reza Faridi-Majidi

Tehran University of Medical Sciences

Elham Arkan ( $\nabla$ earkan@kums.ac.ir)

Kermanshah University of Medical Sciences

Research

Keywords: Cellulose acetate, Chitosan, Nanoparticle, Electrospinning, Infection, Wound dressing

Posted Date: July 14th, 2020

DOI: https://doi.org/10.21203/rs.3.rs-36951/v1

License: (9) (i) This work is licensed under a Creative Commons Attribution 4.0 International License. Read Full License 


\section{Abstract}

This study attempts to fabricate the antibacterial nanofibrous mats composed of cellulose acetate (CA) nanofibers loaded with erythromycin-chitosan nanoparticles (Ery-CS NPs) intended for infected wound dressing. The Ery-loaded CS NPs were prepared by ionic gelation process and then incorporated into the CA electrospun nanofibers (NFs). The characterization of the NPs and mats were investigated by using dynamic light scattering (DLS), scanning electron microscopy (SEM), Attenuated Total Reflection Fourier transform infrared (ATR-FTIR) to show the size distribution, morphology and surface chemistry along with other physiochemical properties including hydrophilicity property, porosity, and water absorption capacity. The antimicrobial activity and cell viability of fibroblast cells were also evaluated. The results indicated that Ery was loaded into CS NPs with high encapsulation efficiency (95\%). The CA NFs (17\%) incorporated with the Ery-CS NPs (12 wt\%) displayed smooth homogenous morphology with $141.7 \pm$ $91.7 \mathrm{~nm}$ average diameter. The relevant analyses revealed that the NPs incorporated in NFs and provided high water holding capacity with high porosity. Finally, Ery-CS NPs/CA mats were able to inhibit the growth of both Gram-positive and Gram-negative bacteria as well as showed no cytotoxic effect on the human dermal fibroblast cells. Overall, our findings concluded that the proposed system could be potentially applied as the proper antibacterial mats for infected wound dressing applications.

\section{Introduction}

Nowadays, Bacteria-caused infections have been exclusively investigated due to the high rates of death. Among these infections, skin and tissue infections (SSTIs) are the greatest broadly known of infections that the yearly touching nearly 15 million people in the united states. $[1,2]$. To conquer this health challenge, nanofibers (NFs) have been widely applied as the wound dressings to provide a suitable matrix with many capabilities containing absorbing exudates, loading one and/or additional therapeutic agents, and releasing drug [2-5]. Besides, nanofibrous scaffolds, established via the electrospinning process, can provide a biodegradable antimicrobial, can reach a great surface area, and display various morphologies $[6,7]$. Electrospinning process also has been taken more attention in the last decades owing to fascinating properties in the variety of applications specifically in wound dressing patches $[8,9]$. These NFs are responsible to solve the problems of predictable DDSs comprising drug degradation in the oral intake, which can be applied to handle various diseases related to human skin wounds [10]. Additionally, electrospun NFs have proposed bright features as the wound dressing mats $[11,12]$. For this purpose, different types of polymers including synthetic, semisynthetic, and natural have been exclusively employed owing to inexpensive cost-effectiveness, nontoxic, simple accessibility, biodegradability, and biocompatibility [13-16].

Cellulose acetate (CA), the acetate ester of cellulose (Scheme 1a), is a synthetic polymer that can be applied as electrospun fibers for various applications specifically drug delivery systems (DDSs). [17-20]. Due to various advantages of CA such as biocompatibility, biodegradability, high hydrolytic stability, and chemical resistance, CA electrospun NFs could be chosen as elite material for drug delivery applications [21]. Furthermore, this polymer is capable to entrap and simultaneous deliver of the high efficiency of 
diverse therapeutics drugs or natural agents $[9,22,23]$. It seems that by blending the natural polymers with CA, these electrospun NFs can be provided the better properties for wound dressing applications [9].

The treatment by using natural polymers comprising chitosan (CS), propolis and starch have been exclusively considered for the wide variety of illnesses [24-27]. Chitosan, (1-4)-2-amino-2-deoxy- $\beta$ - $d$ glucan (Scheme 1b), is a polysaccharide gained from alkaline hydrolysis of chitin with that possesses plentiful proper features for wound dressing applications $[25,26,28]$. Moreover, the non-toxic products of $\mathrm{CS}$, after degradation, are oligosaccharides which can be then extruded or combined to glycosaminoglycans and glycoproteins [26]. CS is a natural water-insoluble polymer that extensively applied for wound healing owing to several advantages including, excellent water absorption capacity, biodegradability, biocompatibility and antibacterial activity $[28,29]$. Thanks to mentioned-properties, chitosan can be exclusively used for the preparation of new products for wound dressing applications [26].

Erythromycin (Ery), is a medium-spectrum antibiotic, achieved by Streptomyces erythreus that contains a 13-carbon ring with two sugars involved by glycosidic linkages (Scheme 1c) [30, 31]. It is very soluble in organic solvents and poorly soluble in water; it is valuable in the remedy of pneumonia, diphtheria, whooping cough, and acne handlings [30-32]. The common dosage for topical administration is about $20 \mathrm{mg} / \mathrm{g}$ [33].

The combination of Ery and natural polymers into electrospun NFs is an attractive issue if wound healing and drug delivery are desired. These systems can provide a novel and effective therapy to protecting the wound site from bacterial infection [30]. It is hypothesized that a proper electrospun nanofiber containing both antibacterial agents and antibacterial NPs could be result in a perfect antibacterial wound dressing material. Therefore, we tried to integrate the advantages of CA electrospun NFs with Ery-loaded CS NPs to improve antibacterial activity for wound healing applications. In this regard, fabrication of polyvinyl alcohol (PVA)/carboxymethyl cellulose (CMC)-ZnO NFs containing Ery was investigated to employ for wound dressing. The results obtained from this study revealed that the proposed system provided excellent antibacterial activity against $S$. aureus and $E$. coli. In vitro study displayed that Ery release from PVA-CMC/ZnO-EM NFs was gradually increased [34].

The major aim of this study was to fabricate an ideal nanofibrous wound dressing mats based on CA loaded with CS/Ery NPs through the electrospinning process. For this purpose, The Ery-loaded CS NPS were made and then incorporated into the CA electrospun nanofibers. Physicochemical properties of nanoparticles and CA NFs were measured by using dynamic light scattering (DLS), scanning electron microscopy (SEM), Attenuated Total Reflection Fourier transform infrared (ATR-FTIR) and contact angle measurement. Finally, the antibacterial activity and biocompatibility of this proposed system were assessed.

\section{Materials And Methods}


Cellulose acetate (CA, acetyl content $39.8 \%$ and $\mathrm{Mn}=30,000$ by GPC), erythromycin (Ery, No E5389) and chitosan (CS, MW: 50,000-190,000, 75-85\% deacetylated) were purchased from Sigma-Aldrich (Missouri, Untied States). Acetic acid, ethanol and sodium triphosphate (TPP) were obtained from Merck Company (Darmstadt, Germany). The cell culture materials such as DMEM/F12, fetal bovine serum, 0.05\% trypsin/EDTA, phosphate buffer saline (PBS), and 3-(4,5-dimethylthiazol-2-yl-2,5diphenyltetrazolium bromide) (MTT) were purchased from Gipco (Marcq-en-Barœul, France). The microbial culture medium nutrient broth, nutrient agar, were also purchased from Oxoid (Basingstocke, UK). Human dermal fibroblast cells were obtained from the Pasteur Institute of Tehran.

\subsection{Synthesize Ery-loaded CS NPs}

Ery loaded CS NPs were synthesized by ionic gelation method previously described [35]. First, CS was dissolved in an aqueous solution of acetic acid (1\% (v/v)) to form $2 \mathrm{mg} / \mathrm{ml}$ of CS solution under overnight stirring at room temperature. Then, Ery $(10-30 \mathrm{mg})$

was mixed with the CS solution and stirred for 1 hour. Next, TPP in water solution ( $0.2 \mathrm{w} / \mathrm{v})$ was injected drop wisely (flow rate $1 \mathrm{~mL} / \mathrm{min}$ ) to the CS solution (TPP to CS: $20 \%(\mathrm{v} / \mathrm{v})$ ) under moderate stirring for 1 hour. After that, the Ery-CS NPs were collected after centrifugation at 10,000 rpm for $1 \mathrm{~h}$ at $4{ }^{\circ} \mathrm{C}$, redispersed in deionized water and freeze-dried.At last, the supernatant was gathered for the quantification of loading and encapsulation efficiency.

\subsection{Fabrication of CA NFs loaded with Ery-CS NPs}

CA NFs loaded with Ery-CS NPs were fabricated under optimized conditions using the electrospinning process. Electrospinning the solutions was carried out using an electrospinning apparatus set at an $18 \mathrm{kV}$ applied voltage, flow rate $1 \mathrm{~mL} / \mathrm{h}$, and a $15 \mathrm{~cm}$ tip-to-collector distance. The NFs were collected on a metallic rotating drum wrapped with a metal foil. According to the given conditions, CA solutions ( $17 \%$ $\mathrm{w} / \mathrm{v}$ ) were prepared with a mixture of acetic acid/water at different proportions 80:20, 90:10 and 100:0 $\mathrm{v} / \mathrm{v}$. Then, the obtained NFs were evaluated which the ratio $90: 10 \mathrm{v} / \mathrm{v}$ was selected as the proper proportion. Following, CA solution (17\% w/v) in acetic acid-water (90:10 v/v) and Ery-CS NPs at different concentration $(5,8,12,15 \mathrm{wt} \%)$ were blended and was produced the electrospun fibers. Finally, the NFs removed from the metal foil and stored for further characterizations and applications.

\subsection{Characterization of the prepared NPs}

\subsubsection{Dynamic light scattering and Zeta potential analyses}

The size and size distribution of Ery-CS NPs were measured by scatteroscope I (K-ONE, Korea) after the preparation of CS NPs. Moreover, the zeta potential of the NPs was determined by electrophoretic light scattering (Zeta sizer, Malvern, UK) at $25^{\circ} \mathrm{C}, 150 \mathrm{~V}$. For this purpose, the NPs were dispersed in phosphate buffer saline ( $\mathrm{pH} 7.4)$, and the zeta potential was measured in triplicate for each sample.

\subsubsection{SEM analysis of the NPs}


The size and morphology of the Ery-CS NPs were also studied by SEM (XL30 Philips, The Netherlands) at an accelerating voltage of $20.0 \mathrm{kV}$ after sputtering gold.

\subsubsection{Encapsulation efficiency and drug loading measurements}

The percentage of encapsulation efficacy (EE \%) of Ery in CS NPs and drug loading (DL\%) were analyzed by UV Vis spectrophotometer (Cecil Instruments Ltd., UK) at $205 \mathrm{~nm}$. The concentration of free Ery in the supernatant was measured based on a previously created calibration curve for Ery and then EE and DL were calculated by using the following equation:

$\mathrm{EE} \%=(\mathrm{A}-\mathrm{B}) / \mathrm{A} \times 100$

$D L \%=A / C \times 100$

Where $A$ is the total amount of Ery, B is the amount of free Ery available in the supernatant, and $\mathrm{C}$ is the weight of NPs after freeze-drying.

\subsection{Characterization of the fabricated NFs}

\subsubsection{Morphology and Size assessment}

The morphology and diameter of the NFs were observed by using a SEM (DSM 960A, Zeiss, Germany) applied at an acceleration voltage of $15 \mathrm{kV}$ and the NFs coated with gold plasma sputter. Image-J software was also used to analyze the NFs diameter distributions.

\subsubsection{Attenuated total reflection FTIR}

The analysis of the functional groups and bonding configurations of the samples were characterized using ATR-FTIRspectroscopy (Bruker 125HR), which was recorded between $600-4000 \mathrm{~cm}^{-1}$ at room temperature.

\subsubsection{Water absorption}

The water absorption capacity of free CA NFs and Ery-CS/CA NFs mats was determined by immersion in water ( $\mathrm{pH} \mathrm{7.4)}$ at $37^{\circ} \mathrm{C}[36]$. The piece of mats precisely weighed and then were immersed for $1,3,6,12$, 24 and 72 hours in the water. After immersion for respective periods, the samples were taken out from the medium, and excess fluid on the surface of each specimen was carefully drained off by filter paper. Afterward, the mats were weighed as wet weight. The water absorption percentage $(W)$ of the mats was calculated using the following equations:

$\mathrm{W}=(\mathrm{W} 1-\mathrm{W} 0) / \mathrm{W} 0 \times 100 \%$

The W0 and W1 define the weight of dried and wet mat, respectively. The mean value was obtained from three parallel samples. 


\subsubsection{Contact-angle measurement}

The hydrophilicity of free CA NFs and Ery-CS/CA NFs mats was determined by water contact angle measurement. The sessile drop technique was performed using a contact angle measuring system (G10, KRUSS, and Germany). For this objective, $4 \mu \mathrm{L}$ distilled water droplet was located on the surface of each mat. The values were reported as the average of three samples for each test.

\subsubsection{Porosity evaluation}

The determination of the porosity of free CA NFs and Ery-CS/CA NFs was measured using the liquid displacement method [37]. The mats immersed in absolute ethanol for 1 hour and then the porosity was measured by the following equation:

Porosity $(\%)=\mathrm{V} 1-\mathrm{V} 2 / \mathrm{V} 2-\mathrm{V} 3 \times 100$

where $\mathrm{V} 1, \mathrm{~V} 2$, and $\mathrm{V} 3$ represent the initial volume of ethanol, the volume after immersing and the volume of the ethanol after the mat removal (after $1 \mathrm{~h}$ ), respectively.

\subsection{Antibacterial activity assessment}

The antibacterial experiments of samples were performed using disc-diffusion and broth microdilution methods against Gram-positive (S. aureus ATCC 25923) and Gram-negative (E. coli ATCC 2592 and $P$. aeruginosa ATCC 12228) bacteria. These micro-organisms commonly found on infectious skin and wounds. In disc-diffusion method, the nanofibrous mats including CA, Ery/CA, CS NPs/CA and Ery-CS NPs/CA, were cut into circular discs and were placed on the surface of nutrient agar plates. The discscontaining plates incubated for $24 \mathrm{~h}$ at $37^{\circ} \mathrm{C}$. Then, the clearance zones were measured in diameter. The broth microdilution method was also applied to determine the minimal inhibitory concentration (MIC) of Ery, CS NPs and Ery-CS NPs [38, 39]. All strains were grown in nutrient broth media adjusted to $10^{6}$ colony-forming units (CFU)/mL, then was added to each tube. After UV sterilization, using the serial dilution method, 10 different concentrations of each sample were added to the bacterial suspensions. All tubes were incubated at $35^{\circ} \mathrm{C}$ for $24 \mathrm{~h}$ in an orbital shaker, and then their turbidity was examined against light. Bacterial suspension without treatment and nutrient broth media were used as a positive and negative control, respectively. The lowest concentration at which inhibit the visible growth was considered as the MIC.

\subsection{Cell viability assay}

The viability of cultured human dermal fibroblast cells (Pasteur Institute of Iran, Tehran, Iran) on CA NFs, Ery/CA NFs, CS/CA NFs and Ery-CS NPs/CA NFs was evaluated using MTT colorimetric assay [40]. The mats were first to cut into proper sizes and placed in each well of the 96-well plate. After sterilizing the mats by UV radiation, the cells were seeded onto the mats at a density of $1 \times 104$ cells/well, followed by incubation for $24 \mathrm{~h}, 48 \mathrm{~h}$, and $72 \mathrm{~h}$. After each incubation time, the culture medium was removed from each well and the wells were washed with PBS three times. Then fresh medium with the MTT $(5 \mathrm{mg} / \mathrm{mL})$ reagent was added to each well followed by incubation for $3 \mathrm{~h}$ at $37^{\circ} \mathrm{C}$. The optical density of each well 
at $570 \mathrm{~nm}$ was measured by an ELISA reader (Perkin-Elmer, USA,). The cell viability was identified by comparing the absorbance of cells cultured on the mats to that of control well having cells. The experiments carried out for each sample in triplicate.

\subsection{Statistical analysis}

All values were reported as the mean \pm standard deviation (SD). Data were analyzed by one- or two-way analysis of variance (ANOVA) by GraphPad Prism 8 software. $P<0.05$ was considered statistically significant $(*: P<0.05)$.

\section{Results And Discussion}

The fabrication of antibacterial wound dressing/matrices is necessary for amelioration of lesions and the prevention of infection in the skin and soft tissues. In this regard, CA electrospun NFs have indicated striking properties to dermal/transdermal or wound dressing applications [9, 23]. Moreover, CS NPs have brought great benefits for the loading/delivery of therapeutics agents and wound dressing materials due to its unique physicochemical and inherent antibacterial properties [41-43]. Herein, we attempt to present the benefits of CA NFs concurrent with the therapeutic effects of CS NPs to delivery of Ery for enhancing antibacterial wound healing applications.

\subsection{Particle size and zeta potential characterization of Ery loaded CS NPs}

The unloaded CS particles and loaded with Ery were analyzed by dynamic light scattering (DLS) technique to obtain the particle size distribution. The resultant plot showed that the mean particle size of unloaded particles was $115 \mathrm{~nm}$ (Fig. 1a) and loaded particles with Ery was $251 \mathrm{~nm}$ (Fig. 1b). The observed difference in the average size of the prepared NPs is probably due to the high drug loading in Ery-CS NPs. Also, different concentration of Ery $(10$ to $30 \mathrm{mg})$ was used to preparation of Ery-CS NPS, which does not significant effect on the size distribution of Ery-CS NPs.

The morphology of loaded CS NPs with the formulation having $30 \mathrm{mg}$ Ery in aqueous phase was observed by SEM, which is shown in Fig. 1c and d. The SEM micrograph was confirmed a spherical shape with smooth surfaces and uniform size of the prepared NPs with around $50 \mathrm{~nm}>$ in size. Furthermore, the zeta potential of CS NPs and Ery-CS NPs was about $+14.7 \mathrm{mV}$ (Fig. 1e) and $+14.9 \mathrm{mV}$ (Fig. 1f), respectively, which is considered a reasonable surface charge for CS NPs due to positive charge of functional groups in CS chains. Besides, positively charged NPs indicated that can be adsorbed on the bacterial surface and closely connected with bacteria [44].

\subsection{Loading and encapsulation efficiency}

The high concentration of Ery $(30 \mathrm{mg}$ ) resulted in higher EE and DL, as a result, this preparation condition was chosen as the optimal formula and used for all further experiments including EE, DL and electrospinning. EE and DL of the optimized Ery loaded CS NPs were measured to be $95.3 \pm 3.1 \%$ and 
$41.14 \pm 0.05 \%$, respectively. Hence, Ery was well encapsulated into CS NPs, and indicated a high amount of Ery could incorporate in CS NPS.

\subsection{The optimum condition for electrospun fiber mats of CA and Ery-CS NPs/CA}

Prior to the addition of Ery-CS NPs to CA solution for electrospinning, CA solution (17\% w/v) with the different ratios of acetic acid/water solvents were prepared and the diameter, morphology and their fiberforming abilities were tested through electrospinning. Figure $2 a-c$ shows the SEM micrograph images of CA electrospun fibers at different ratio of the solvents as follows: 80:20 v/v (a), 90:10 v/v (b) and 100:0 $\mathrm{v} / \mathrm{v}$ (c); the diameter distribution of the prepared NFs was $1133.8 \pm 446.7 \mathrm{~nm}, 269 \pm 74.6 \mathrm{~nm}$, and $336.3 \pm$ $133.9 \mathrm{~nm}$, respectively. Moreover, the SEM micrographs revealed that the electrospinning of CA (17\% w/v) produced the smooth, cylindrical, ribbon-shaped and bead-free NFs. Whereas increasing the acetic acid concentration from 90 to $100 \% \mathrm{v} / \mathrm{v}$ led to the formation of non-uniform CA NFs in diameter and morphology (Fig. 2c). The reason why the morphology of the electrospun fibers was changed is rooted in the fact that changing acetic acid concentration is associated with the rheological behavior of the CA solution as well as with the stretching of the electrospinning jet $[45,46]$. Subsequently, the prepared NFs with $90: 10 \mathrm{v} / \mathrm{v}$ acetic acid/water was used for further work due to the lower diameter, proper morphology and uniform structure.

In the following, different concentration of Ery-CS NPs (5-8-12-15 wt\%) was incorporated in the optimized CA solution and then their fiber-forming abilities by electrospinning as well as the diameter distribution and morphology were evaluated. The obtained SEM micrographs along with their diameter distributions are illustrated in Fig. 3a-d. The morphological observation revealed that the CA solution containing 5 to 15 wt\% of Ery-CS NPs generated fibers with different morphologies. Electrospinning of CA having 5 wt\% of the NPs produced relatively uniform and bead-free NFs with the diameter distribution of $204.6 \pm$ $67.7 \mathrm{~nm}$ (Fig. 3a). The more uniform and cylindrical bead-free fibers with diameter distribution of $210 \pm$ $72.6 \mathrm{~nm}$ were formed while the NPs concentration was augmented to $8 \mathrm{wt} \%$ (Fig. 3b). Increasing concentration of the NPs to $12 \mathrm{wt} \%$ resulted in a blend of cylindrical and flat fibers with negligible beads of diameter distribution $141.7 \pm 91.7 \mathrm{~nm}$ as depicted in Fig. 3c. As the concentration of the NPs increased to 15 wt\% generated non-continuous, ribbon or flat-shaped fibers with elongated beads (Fig. 3d), which could reduce the active surface area of

fibers [45] and is not suitable for our purposes. The morphology of the prepared fibers was affected by the incorporated amount of the NPs. Besides, the amounts of the NPs higher than 12 wt\% not produced the proper fibers. This is probably due to the escalated viscoelasticity of the solution and the lack of CA chains entanglement in the solution which is crucial for electrospinning. Finally, the mats containing $12 \mathrm{wt} \%$ of the NPs due to the lowest diameter, unique morphology, and maximum loading in the NFs were selected and employed to further use. Also, under the same condition, $12 \mathrm{wt} \%$ of Ery was incorporated in CA NFs for use in relevant tests.

\subsection{ATR-FTIR Characterization}


ATR-FTIR spectroscopy analysis was conducted to characterize the surface functional groups and the interaction between the constituted components of the Ery-CS NPs/CA NFs. The spectra are shown in Fig. 4a. The spectrum of CA NFs (Fig. 4a 1) displayed characteristic bands at approximately $1040 \mathrm{~cm}^{-1}$ and $1230 \mathrm{~cm}^{-1}$ (C-O-C stretching of ether groups), $1728 \mathrm{~cm}^{-1}$ ( $\mathrm{C}=0$ stretching of acetyl groups) and a broad absorption band at $3300-3500 \mathrm{~cm}^{-1}(\mathrm{O}-\mathrm{H}$ stretching) $[47,48]$. The characteristic peak of Ery (Fig. 4a 2) appeared at $3475 \mathrm{~cm}^{-1}$ for (O-H stretching), $2944 \mathrm{~cm}^{-1}$ for (C-H stretching), $1729 \mathrm{~cm}^{-1}$ for ( $\mathrm{C}=0$ stretching), $1369 \mathrm{~cm}^{-1}$ for $\left(\mathrm{CH}_{2}, \mathrm{CH}_{3}\right)$, and $1167 \mathrm{~cm}^{-1}$ and $1040 \mathrm{~cm}^{-1}$ for (ether group) [49, 50]. The spectrum of CS NPs (Fig. 4a 3) presents characteristic absorption peaks located at $1040 \mathrm{~cm}^{-1}$ and $1234 \mathrm{~cm}^{-1}$ correspond to the stretch vibration of $\mathrm{C}-\mathrm{O}$ bond, $1639 \mathrm{~cm}^{-1}$ related to the $\mathrm{N}-\mathrm{H}$ bending vibration, $2926 \mathrm{~cm}^{-1}$ corresponds to $\mathrm{CH}_{2}$ stretching vibration, and a peak at 3500 to $3200 \mathrm{~cm}^{-1}$ corresponds to $-\mathrm{OH}$ stretching of alcoholic and phenolic groups, which are in agreement with the literature [51-53]. In the FTIR spectra of Ery-CS NPs (Fig. 4a 4), it is clear that the characteristic peaks of CS NPs and Ery are both presented in the Ery-CS NPs, which demonstrated the CS NPs were loaded with Ery. The spectrum of the CA NFs incorporated with 12 wt\% Ery-CS NPs showed both distinctive peaks of CA NFs and the characteristic bands attributed to Ery-CS NPs (Fig. 4a 5), indicating the NPs were efficiently loaded on the CA NFs. Besides, the widening of absorption peaks was detected in the region of $3100-3600 \mathrm{~cm}^{-1}$ related to the stretching of intermolecular hydrogen bonds of hydroxyl groups (-OH) as well as the peak related to the stretching of acetyl groups is weakened. These properties are generally caused by intermolecular interactions, as well as due to the presence of physical interactions between CA and Ery-CS NPs.

\subsection{Determination of Porosity}

The proposed NFs with higher surface area and higher porosity was exclusively applied for antibacterial wound dressing. The porosity measurements revealed that the CA NFs and Ery-CS NPs/CA NFs possess $90.03 \pm 1.5 \%$ and $91.3 \pm 0.9 \%$ porosity of the total mat volume, respectively. The resultant NFs mats exhibit a remarkably high porosity, as well as the addition of Ery-CS NPs, caused a slight increment in porosity, however, the changes between porosity values are not statistically significant. The presence of large volume of porosity would be helpful for the exchange of oxygen and nutrients to the interior of the wound dressing [54].

\subsection{Contact angle measurement}

An appropriate wound dressing should be hydrophilic to be capable of absorbing the wound exudate and maintaining the moisture levels at the wound bed [55]. The contact angle of a water droplet on the CA NF mats and Ery-CS NPs/CA NF mats are shown in Fig. $4 \mathrm{~b}$ during the period of 1 to $10 \mathrm{~s}$. The measured contact-angle of CA mats (Fig. $4 \mathrm{~b} 1$ ) was found to be $116.5^{\circ}, 77.8^{\circ}, 63.3^{\circ}$ and $0^{\circ}$, and also for Ery-CS NPs/CA mats (Fig. 4b 2) was found to be $100.7^{\circ}, 63.7^{\circ}, 46.5^{\circ}$ and $0^{\circ}$ in $10,5,2$ and $1 \mathrm{~s}$, respectively. Although CA is hydrophobic, water drops rapidly penetrate into the CA mats because of its highly porous 
structure [27]. Moreover, the accumulation of the NPs into CA NFs led to a decrease in the contact angle values. This could be due to the presence of Ery-CS NPs that increased surface hydrophilicity of the mats.

\subsection{Water absorption ability}

As the other valuable characteristics of a wound dressing, water absorption was measured and the results were shown in Fig. 4c. The water holding capacity of CA mats reached to about $206 \%$ and $301 \%$ in the 1 and $48 \mathrm{~h}$ soaking time, and Ery-CA NPs/CA mats reached to about $276 \%$ and $491 \%$ in the 1 and $48 \mathrm{~h}$ soaking time, respectively. After $48 \mathrm{~h}$ immersion, the Ery-CA NPs/CA mats exhibited a high water absorption capacity of about $500 \%$ and about $200 \%$ more than CA NFs, which is due to the high wateruptake ability of CS NPs [56]. The Ery-CA NPs/CA mats provided a significant water-holding capacity, which can be applied as a wound dressing to absorb the wound fluidslexudates.

\subsection{Antibacterial activity}

The antibacterial activity of CA, Ery/CA, CS NPs/CA and Ery-CS NPs/CA fiber mats against the both positive and negative bacteria was tested by using the disk diffusion method. No zone of inhibition was observed near the disk made only CA nanofibrous mats in the three strains of bacteria (Fig. 5a-c 1). Nevertheless, such nanofibrous mats can create perfect blocks and pores that can prevent bacterial penetration and exogenous infections. The diameter of inhibition ring was around $20 \mathrm{~mm}, 18 \mathrm{~mm}$ and $15 \mathrm{~mm}$ for Ery/CA mats (Fig. 5a-c 2) and was around $25 \mathrm{~mm}, 22 \mathrm{~mm}$ and $18 \mathrm{~mm}$ for the CA mats loaded CS NPs (Fig. 5a-c 3) against S. aureus, E. coli and P. aeruginosa respectively. In case of Ery-CS NPs/CA mats, the diameter of the inhibition zones reached $30 \mathrm{~mm}, 25 \mathrm{~mm}$ and $20 \mathrm{~mm}$, as shown in Fig. 5a-c 4 . These results demonstrated the superior antibacterial activity of the Ery-CS NPs/CA mats in comparison to Ery/CA and CS NPs/CA nanofibrous mats that is probably due to the merged antibacterial activity of Ery and CS NPS.

Subsequently, the antibacterial activity of the constituents of Ery-CS NPs/CA mats were also investigated by MIC testing that the results are shown in Table 1. The applied strains possessed MIC values $\geq$ $100 \mu \mathrm{g} / \mathrm{mL}$ and presented highly resistant to Ery. CS NPs showed high bactericidal activity against both positive/negative strains, however, indicated the lower antibacterial effect on the negative strains than the positive strain. The antibacterial activity of CS NPs is resulted from the alteration of membrane penetrability leading to membrane disruption and leakage of cytoplasm [57]. Furthermore, the MIC value of Ery-CS NPs was about $5 \mu \mathrm{g} / \mathrm{mL}$ against $S$. aureus, and also 20 and $80 \mu \mathrm{g} / \mathrm{mL}$ against $E$. coli and $P$. aeruginosa (Table 2), which is lower than Ery and CS NPs. This could be due to the combinational antibacterial effects of the CS NPs and Ery. As a result, the findings confirmed that the developed nanofibrous mat provides a high antibacterial efficiency and could be operative to treat infected wounds. 
Table 1

Antibacterial MIC test results of the samples against

the Gram positive/negative bacteria (The value

mentioned as a mean value).

\begin{tabular}{|llll|}
\hline & \multicolumn{3}{l}{ MIC $(\mu \mathrm{g} / \mathrm{ml})$} \\
\cline { 2 - 4 } & S. aureus & E. coli & P. aeruginosa \\
\hline Ery & 100 & 200 & 400 \\
\hline CS NP & 10 & 40 & 160 \\
\hline Ery-CS NPs & 5 & 20 & 80 \\
\hline
\end{tabular}

\subsection{Cellular biocompatibility}

To confirm that the prepared nanofibrous mats (loaded or not loaded), have any measurable impact on the growth of human dermal fibroblast cells, the cell viability was determined using MTT-based assay after 48 and $72 \mathrm{~h}$ incubation. The obtained results revealed that cell viability of CA and Ery-CS NPs/CA mats slightly declined that were not significant statistically compared to the control group after $48 \mathrm{~h}$ incubation. But, however, After $72 \mathrm{~h}$ incubation, cell

growth was higher on Ery-CS NPs/CA and CS NPs loaded CA nanofibrous mats than the control group. This could be owing to the greater hydrophilic nature of the CS NPs (Fig. 6). Besides, in case of Ery/CA mats, cell proliferation decreased which was probably due to adverse effects of Ery on the cell growth on the fibroblasts. There was no significant distinction in cell viability between the different groups compared to the control group, indicating the biocompatibility of the proposed nanofibrous mats. The results showed that Ery-CS NPs/CA NFs can be potentially applied as biocompatible and biodegradable mat for wound dressing applications.

\section{Conclusions}

This study seeks to integrate the potential antibacterial activity of CS NPs and Ery incorporated into CA electrospun NFs to develop a suitable antibacterial wound dressing. The optimized solvent ratio of acetic acid: water $(90: 10 \mathrm{v} / \mathrm{v})$ was established to fabricate CA electrospun NFs mat. Ery loaded CS NPs was synthesized by ionic gelation method that exhibited the nano-scale size with reasonable zeta potential and high encapsulation efficiency and drug loading. Afterward, different concentrations of Ery-CS NPS were incorporated into the CA NFs that the $12 \mathrm{wt} \%$ of NPs produced the more appropriate size distribution and morphology specifications. Moreover, the physicochemical characteristics of the fabricated mats were confirmed by ATR-FTIR, porosity, contact angle and water absorption analyses. Ery-CS NPs/CA mats showed the effective antibacterial activity toward both Gram-positive and Gram-negative bacteria. The cell viability assay showed non-cytotoxic effects on human fibroblasts, confirming biocompatibility of the nanofibrous mats. All these findings indicate that these Ery-CS NPs/ CA mats can be employed as an efficient nanofiber-based antibacterial wound dressing material. 


\section{Declarations}

Acknowledgements:

This study was supported by Tehran University of Medical Sciences.

\section{Authors' Contributions}

MD: Performed experiments, analyzed data, wrote the manuscript, conceptualization and visualization. HM: Participated and assisted in data analysis and experiments, conceptualization, visualization, wrote the manuscript and resources. MD: Participated and assisted in experiments and conceptualization. KK: Conceptualization, wrote the manuscript, visualization and resources. RFM: Conceptualization, supervision and resources. EA: Supervision, conceptualization, visualization, wrote the manuscript and resources. All authors read and approved the final manuscript

\section{Funding}

This work was supported by Kermanshah University of Medical Sciences, Grant No. 3006728.

\section{Ethics approval and consent to participate}

Not applicable.

\section{Consent for publication}

The authors agreed to submit this study.

\section{Competing interests}

The authors declare that they have no competing interests.

\section{References}

1. Kaye KS, Petty LA, Shorr AF, Zilberberg MD. Current epidemiology, etiology, and burden of acute skin infections in the United States. Clinical Infectious Diseases. Oxford University Press US; 
2019;68:S193-9.

2. Simões D, Miguel SP, Ribeiro MP, Coutinho P, Mendonça AG, Correia IJ. Recent advances on antimicrobial wound dressing: A review. Eur J Pharm Biopharm. 2018;127:130-41.

3. Sridhar R, Lakshminarayanan R, Madhaiyan K, Barathi VA, Limh KHC, Ramakrishna S. Electrosprayed nanoparticles and electrospun nanofibers based on natural materials: Applications in tissue regeneration, drug delivery and pharmaceuticals. Chem Soc Rev. 2015;44:790-814.

4. Agrahari V, Agrahari V, Meng J, Mitra AK. Electrospun Nanofibers in Drug Delivery: Fabrication, Advances, and Biomedical Applications. Emerging Nanotechnologies for Diagnostics, Drug Delivery and Medical Devices. Elsevier; 2017. p. 189-215.

5. Saghazadeh S, Rinoldi C, Schot M, Kashaf SS, Sharifi F, Jalilian E, et al. Drug delivery systems and materials for wound healing applications. Adv Drug Deliv Rev. 2018;127:138-66.

6. Keirouz A, Radacsi N, Ren Q, Dommann A, Beldi G, Maniura-Weber K, et al. Nylon-6/chitosan core/shell antimicrobial nanofibers for the prevention of mesh-associated surgical site infection. Journal of Nanobiotechnology. 2020;18:51.

7. Su Z, Ding J, Wei G. Electrospinning: a facile technique for fabricating polymeric nanofibers doped with carbon nanotubes and metallic nanoparticles for sensor applications. RSC Advances The Royal Society of Chemistry. 2014;4:52598-610.

8. Li W, Li X, Wang T, Li X, Pan S, Deng H. Nanofibrous mats layer-by-layer assembled via electrospun cellulose acetate and electrosprayed chitosan for cell culture. Eur Polymer J. 2012;48:1846-53.

9. Khoshnevisan K, Maleki H, Samadian H, Shahsavari S, Sarrafzadeh MH, Larijani B, et al. Cellulose acetate electrospun nanofibers for drug delivery systems: Applications and recent advances. Carbohydrate Polymers. 2018.

10. Torres-Martinez EJ, Cornejo Bravo JM, Serrano Medina A, Pérez González GL, Villarreal Gómez LJ. A Summary of Electrospun Nanofibers as Drug Delivery System: Drugs Loaded and Biopolymers Used as Matrices. Curr Drug Deliv. 2018;15:1360-74.

11. Balaji A, Jaganathan SK, Ismail AF, Rajasekar R. Fabrication and hemocompatibility assessment of novel polyurethane-based bio-nanofibrous dressing loaded with honey and Carica papaya extract for the management of burn injuries. International journal of nanomedicine Dove Medical Press. 2016;11:4339-55.

12. Vijayakumar V, Samal SK, Mohanty S, Nayak SK. Recent advancements in biopolymer and metal nanoparticle-based materials in diabetic wound healing management. Int J Biol Macromol. 2019;122:137-48.

13. Venugopal J, Ramakrishna S. Applications of polymer nanofibers in biomedicine and biotechnology. Applied Biochemistry and Biotechnology - Part A Enzyme. Engineering Biotechnology. 2005;125:147-57.

14. Thakkar S, Misra M. Electrospun polymeric nanofibers: New horizons in drug delivery. Eur J Pharm Sci. 2017;107:148-67. 
15. Hu X, Liu S, Zhou G, Huang Y, Xie Z, Jing X. Electrospinning of polymeric nanofibers for drug delivery applications. J Controlled Release. 2014;185:12-21.

16. Khalf A, Madihally SV. Recent advances in multiaxial electrospinning for drug delivery. European Journal of Pharmaceutics and Biopharmaceutics. 2017. p. 1-17.

17. Liakos IL, Holban AM, Carzino R, Lauciello S, Grumezescu AM. Electrospun Fiber Pads of Cellulose Acetate and Essential Oils with Antimicrobial Activity. Nanomaterials. 2017;7:84.

18. Kurečič M, Maver T, Virant N, Ojstršek A, Gradišnik L, Hribernik S, et al. A multifunctional electrospun and dual nano-carrier biobased system for simultaneous detection of $\mathrm{pH}$ in the wound bed and controlled release of benzocaine. Cellulose. 2018;25:7277-97.

19. Baharifar H, Honarvarfard E, Haji Malek-kheili M, Maleki H, Barkhi M, Ghasemzadeh A, et al. The Potentials and Applications of Cellulose Acetate in biosensor technology. Nanomedicine Research Journal. 2017;2:216-23.

20. Suwantong O, Opanasopit P, Ruktanonchai U, Supaphol P. Electrospun cellulose acetate fiber mats containing curcumin and release characteristic of the herbal substance. Polymer. 2007;48:7546-57.

21. Farzamfar S, Naseri-Nosar M, Vaez A, Esmaeilpour F, Ehterami A, Sahrapeyma H, et al. Neural tissue regeneration by a gabapentin-loaded cellulose acetate/gelatin wet-electrospun scaffold. Cellulose. 2018;25:1229-38.

22. Son WK, Youk JH, Lee TS, Park WH. Electrospinning of ultrafine cellulose acetate fibers: studies of a new solvent system and deacetylation of ultrafine cellulose acetate fibers. J Polym Sci Part B: Polym Phys. 2004;42:5-11.

23. Konwarh R, Karak N, Misra M. Electrospun cellulose acetate nanofibers: The present status and gamut of biotechnological applications. Biotechnology Advances. 2013.

24. Masina N, Choonara YE, Kumar P, du Toit LC, Govender M, Indermun S, et al. A review of the chemical modification techniques of starch. Carbohyd Polym. 2017;157:1226-36.

25. Huang B, Liu M, Zhou C. Chitosan composite hydrogels reinforced with natural clay nanotubes. Carbohyd Polym. 2017;175:689-98.

26. Pellá MCG, Lima-Tenório MK, Tenório-Neto ET, Guilherme MR, Muniz EC, Rubira AF. Chitosan-based hydrogels: From preparation to biomedical applications. Carbohyd Polym. 2018;196:233-45.

27. 10.1016/j.ijbiomac.2019.08.207

Khoshnevisan K, Maleki H, Samadian H, Doostan M, Khorramizadeh MR. Antibacterial and antioxidant assessment of cellulose acetate/polycaprolactone nanofibrous mats impregnated with propolis. International Journal of Biological Macromolecules [Internet]. Elsevier B.V.; 2019;140:12608. Available from: https://doi.org/10.1016/j.ijbiomac.2019.08.207.

28. Ehterami A, Salehi M, Farzamfar S, Samadian H, Vaez A, Ghorbani S, et al. Chitosan/alginate hydrogels containing Alpha-tocopherol for wound healing in rat model. Journal of Drug Delivery Science Technology. 2019;51:204-13.

29. Naseri-Nosar M, Farzamfar S, Salehi M, Vaez A, Tajerian R, Azami M. Erythropoietin/aloe verareleasing wet-electrospun polyvinyl alcohol/chitosan sponge-like wound dressing: In vitro and in vivo 
studies. Journal of Bioactive and Compatible Polymers. Sage Publications Sage UK: London; 2018;33:pp. 269-81.

30. de Souza RFB, de Souza FCB, Moraes ÂM. Polysaccharide-based membranes loaded with erythromycin for application as wound dressings. Journal of Applied Polymer Science. John Wiley \& Sons, Ltd; 2016;133.

31. Enyuan Q, Mingpeng X, Luoman G, Jinghua G, Yu L, Wentao L, et al. Erythromycin combined with corticosteroid reduced inflammation and modified trauma-induced tracheal stenosis in a rabbit model. Therapeutic Advances in Respiratory Disease. SAGE Publications Ltd STM; 2018;12:1753466618773707.

32. Scott MJ, Davis RJ, Belikoff EJ. Genetically engineered larvae for wound healing. Google Patents; 2018.

33. Hamilton RJ. Tarascon Pocket Pharmacopoeia. Jones \& Bartlett Publishers; 2012.

34. Darbasizadeh B, Fatahi Y, Feyzi-barnaji B, Arabi M, Motasadizadeh H, Farhadnejad H, et al. Crosslinked-polyvinyl alcohol-carboxymethyl cellulose/ZnO nanocomposite fibrous mats containing erythromycin (PVA-CMC/ZnO-EM): Fabrication, characterization and in-vitro release and antibacterial properties. Int J Biol Macromol. 2019;141:1137-46.

35. Divya K, Jisha MS. Chitosan nanoparticles preparation and applications. Environmental Chemistry Letters. 2018.

36. Chanda A, Adhikari J, Ghosh A, ... SC-I journal of, 2018 undefined. Electrospun chitosan/polycaprolactone-hyaluronic acid bilayered scaffold for potential wound healing applications. Elsevier [Internet]. [cited 2020 Feb 21]; Available from: https://www.sciencedirect.com/science/article/pii/S0141813018304008.

37. Chakraborty PK, Adhikari J, Saha P. Facile fabrication of electrospun regenerated cellulose nanofiber scaffold for potential bone-tissue engineering application. Int J Biol Macromol. 2019;122:644-52.

38. Abbaspour M, ... BM-J journal. 2015 undefined. Evaluation of the antimicrobial effect of chitosan/polyvinyl alcohol electrospun nanofibers containing mafenide acetate. ncbi.nlm.nih.gov [Internet]. [cited 2020 Mar 7]; Available from: https://www.ncbi.nlm.nih.gov/pmc/articles/PMC4644308/.

39. Zeighampour F, Alihosseini F, Morshed M, Rahimi AA. Comparison of prolonged antibacterial activity and release profile of propolis-incorporated PVA nanofibrous mat, microfibrous mat, and film. Journal of Applied Polymer Science. 2018.

40. Eskandarinia A, Kefayat A, Gharakhloo M, Agheb M, Khodabakhshi D, Khorshidi M, et al. A propolis enriched polyurethane-hyaluronic acid nanofibrous wound dressing with remarkable antibacterial and wound healing activities. International Journal of Biological Macromolecules [Internet]. 2020;149:467-76. Available from: https://linkinghub.elsevier.com/retrieve/pii/S0141813019373787.

41. Ueno H, Mori T, Fujinaga T. Topical formulations and wound healing applications of chitosan. Advanced Drug Delivery Reviews [Internet]. 2001 [cited 2020 Mar 7];52:105-15. Available from: https://www.sciencedirect.com/science/article/pii/S0169409X01001892. 
42. Ahmed T, Aljaeid B. Preparation, characterization, and potential application of chitosan, chitosan derivatives, and chitosan metal nanoparticles in pharmaceutical drug delivery. Drug Design, Development and Therapy [Internet]. 2016 [cited 2020 Mar 7];10:483. Available from: https://www.ncbi.nlm.nih.gov/pmc/articles/PMC4734734/.

43. Harris M, Alexander C, Wells CM, Bumgardner JD, Carpenter DP, Jennings JA. Chitosan for the delivery of antibiotics. Chitosan Based Biomaterials [Internet]. Elsevier; 2017 [cited 2020 Mar 7]. p. 147-73. Available from: https://linkinghub.elsevier.com/retrieve/pii/B9780081002285000067.

44. Wang L, Hu C, Shao L. The antimicrobial activity of nanoparticles: present situation and prospects for the future. International Journal of Nanomedicine [Internet]. 2017;Volume 12:1227-49. Available from: https://www.dovepress.com/the-antimicrobial-activity-of-nanoparticles-present-situation-andpros-peer-reviewed-article-IJN.

45. 10.1007/s12034-019-1857-6

Majumder S, Matin MA, Sharif A, Arafat MT. Understanding solubility, spinnability and electrospinning behaviour of cellulose acetate using different solvent systems. Bulletin of Materials Science [Internet]. 2019;42:171. Available from: http://link.springer.com/10.1007/s12034-019-18576.

46. Haider A, Haider S, Kang I-K. A comprehensive review summarizing the effect of electrospinning parameters and potential applications of nanofibers in biomedical and biotechnology. Arabian Journal of Chemistry [Internet]. 2018;11:1165-88. Available from: https://linkinghub.elsevier.com/retrieve/pii/S1878535215003275.

47. $10.1007 / \mathrm{s} 10570-018-1921-1$

Sharaf S, El-Naggar ME. Eco-friendly technology for preparation, characterization and promotion of honey bee propolis extract loaded cellulose acetate nanofibers in medical domains. Cellulose [Internet]. Springer Netherlands; 2018 [cited 2020 Mar 26];25:5195-204. Available from: http://link.springer.com/10.1007/s10570-018-1921-1.

48. Shalaby TI, El-Kady MF, Zaki AEHM, El-Kholy SM. Preparation and application of magnetite nanoparticles immobilized on cellulose acetate nanofibers for lead removal from polluted water. Water Science and Technology: Water Supply [Internet]. 2017;17:176-87. Available from: https://iwaponline.com/ws/article/17/1/176-187/29994.

49. Ali M, Sherazi STH, Mahesar SA. Quantification of erythromycin in pharmaceutical formulation by transmission Fourier transform infrared spectroscopy. Arabian Journal of Chemistry [Internet]. 2014;7:1104-9. Available from: https://linkinghub.elsevier.com/retrieve/pii/S1878535212002195.

50. 10.1007/s13346-017-0450-z

Alavi T, Rezvanian M, Ahmad N, Mohamad N, Ng S-F. Pluronic-F127 composite film loaded with erythromycin for wound application: formulation, physicomechanical and in vitro evaluations. Drug Delivery and Translational Research [Internet]. 2019;9:508-19. Available from: http://link.springer.com/10.1007/s13346-017-0450-z. 
51. Ayodele $\mathrm{O}$, Okoronkwo AE, Oluwasina OO, Abe TO. Utilization of blue crab shells for the synthesis of chitosan nanoparticles and their characterization. Songklanakarin Journal of Science and Technology. 2018.

52. OH J-W, Chun SC, Chandrasekaran M. Preparation and In Vitro Characterization of Chitosan Nanoparticles and Their Broad-Spectrum Antifungal Action Compared to Antibacterial Activities against Phytopathogens of Tomato. Agronomy [Internet]. 2019;9:21. Available from: https://www.mdpi.com/2073-4395/9/1/21.

53. Zhou SF, Han XJ, Liu YQ. SWASV performance toward heavy metal ions based on a high-activity and simple magnetic chitosan sensing nanomaterials. Journal of Alloys and Compounds. 2016.

54. Microbiological Applications of Bio-Based Porous Materials Udenni Gunathilake T, Ching Y, Ching K, Chuah C, Abdullah L. Biomedical. and Microbiological Applications of Bio-Based Porous Materials: A Review. Polymers [Internet]. 2017;9:160. Available from: http://www.mdpi.com/2073-4360/9/5/160.

55. Mayet N, Choonara YE, Kumar P, Tomar LK, Tyagi C, Du Toit LC, et al. A comprehensive review of advanced biopolymeric wound healing systems. Journal of Pharmaceutical Sciences. 2014.

56. Szymańska E, Winnicka K. Stability of chitosan - A challenge for pharmaceutical and biomedical applications. Marine Drugs. 2015.

57. Qi L, Xu Z, Jiang X, Hu C, Zou X. Preparation and antibacterial activity of chitosan nanoparticles. Carbohydrate Research. 2004.

\section{Figures}



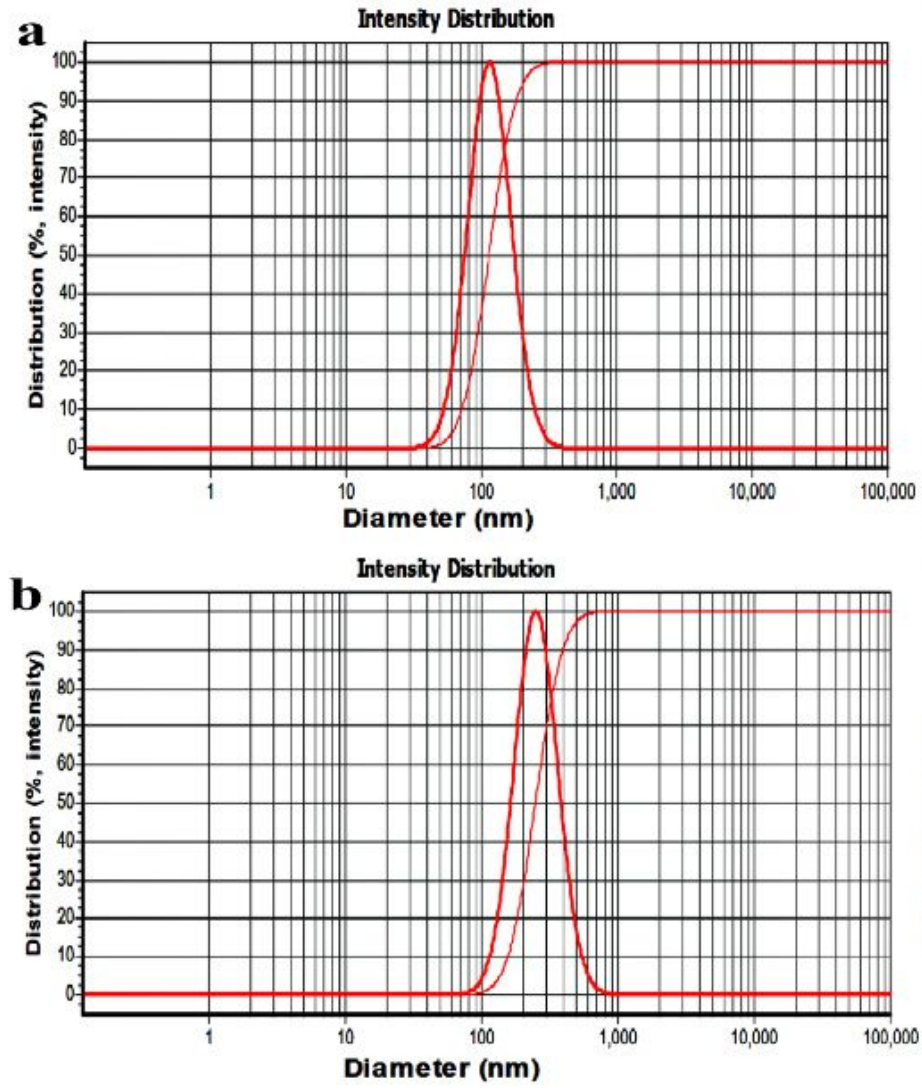
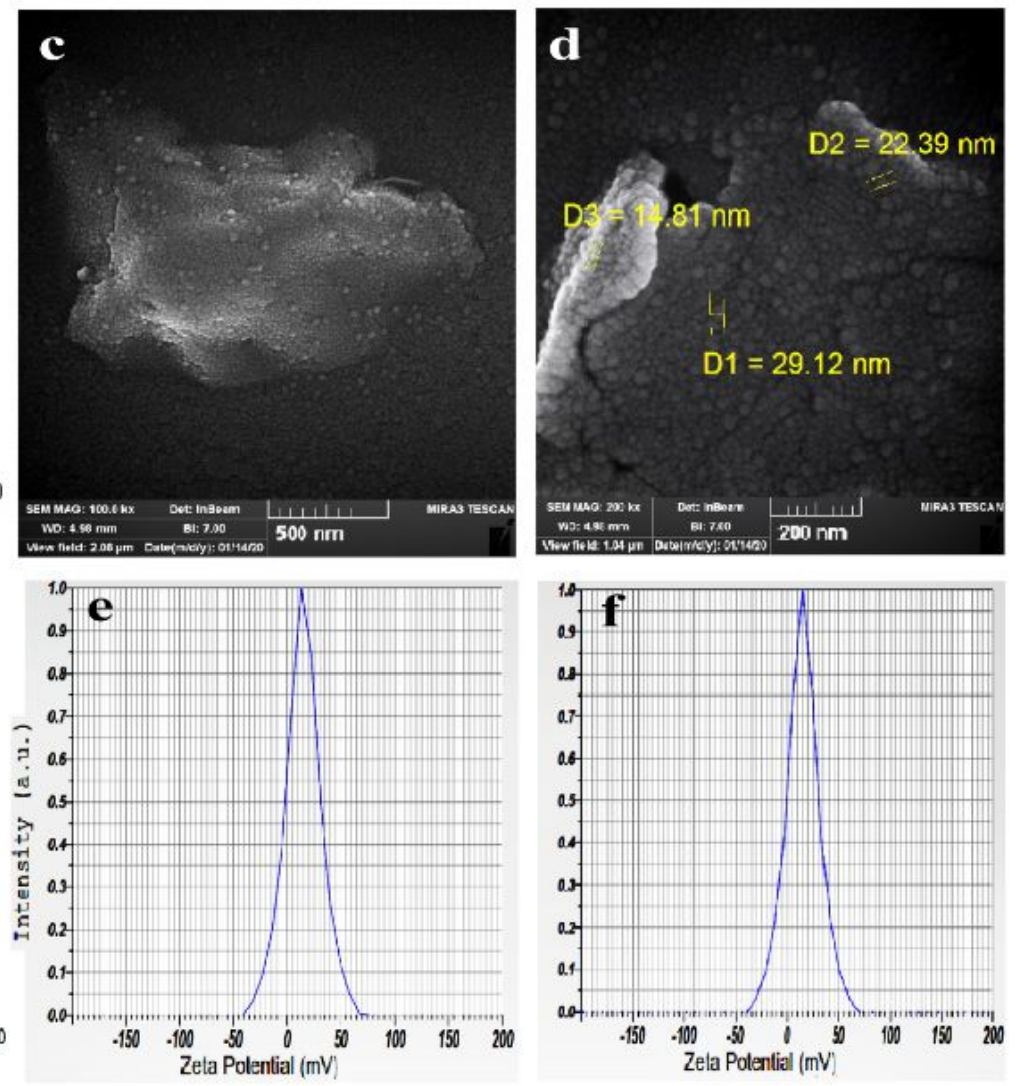

Figure 1

Particle size distribution of CS NPs (a) and Ery-CS NPs (b); SEM micrograph of Ery-CS NPs (c and d); and zeta potential distribution of CS NPs (e) and Ery-CS NPs (f). 

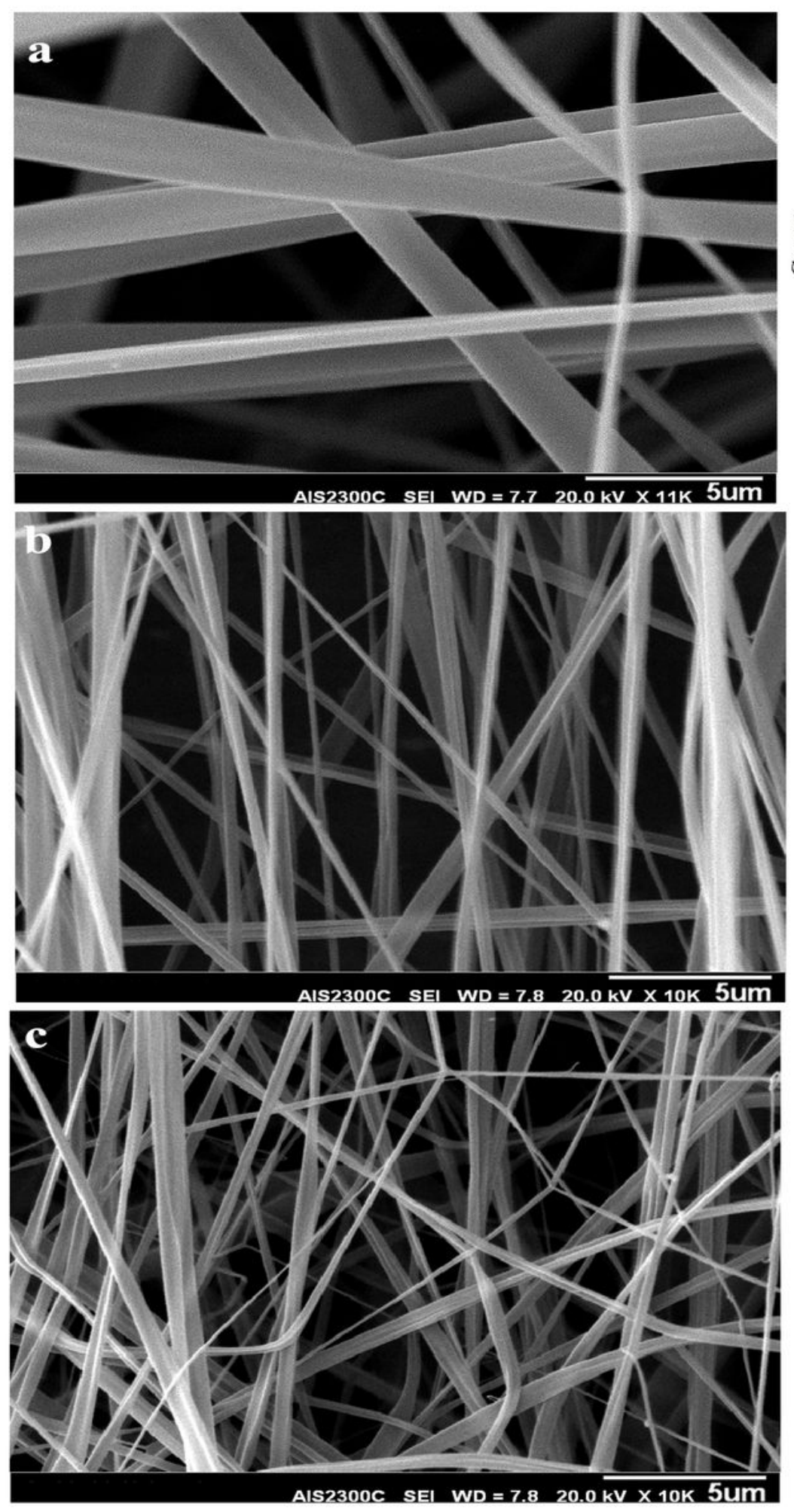
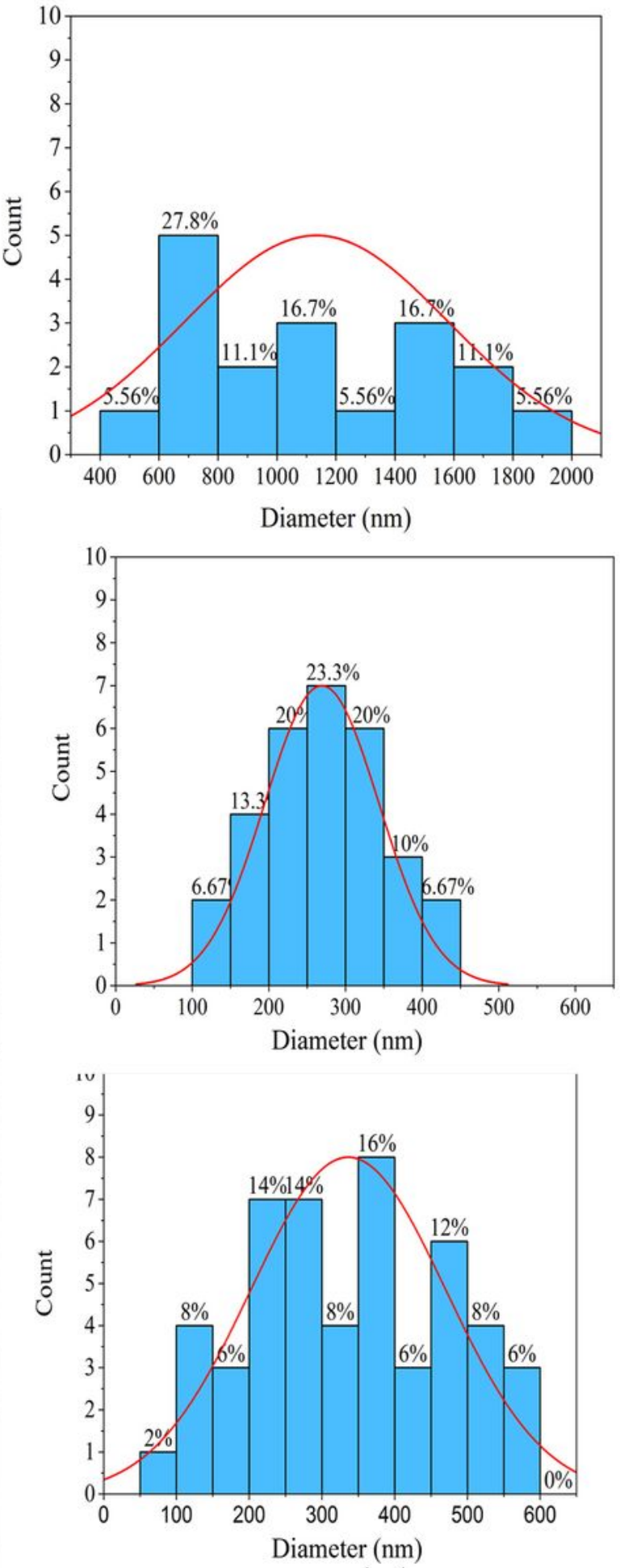

\section{Figure 2}

Morphologies of CA electrospun fibers $(17 \% \mathrm{w} / \mathrm{v})$ at different ratio of acetic acid/water: $80: 20 \mathrm{v} / \mathrm{v}(\mathrm{a})$, 90:10 v/v (b) and 100:0 v/v (c), with their diameter histograms for each beside it. 

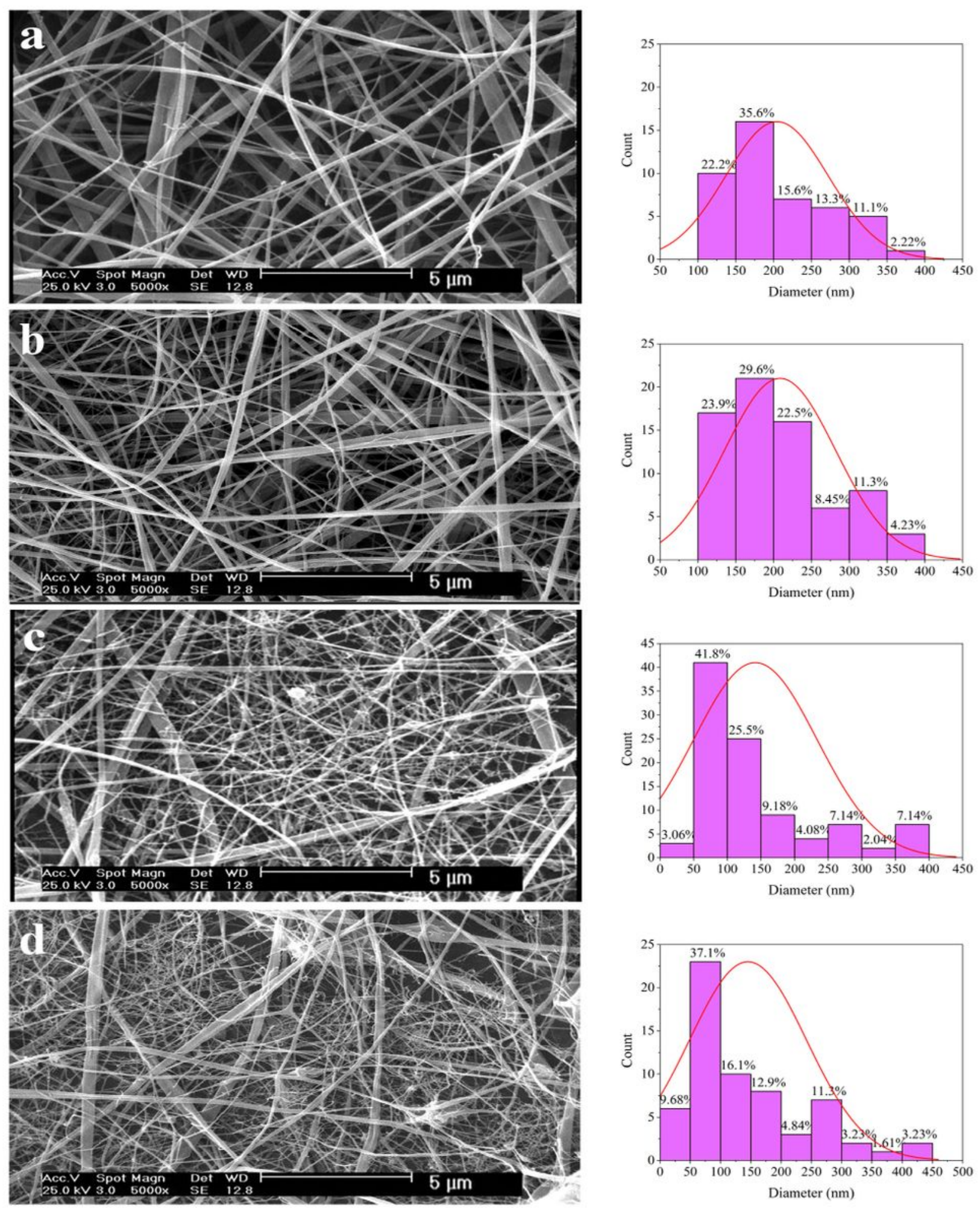

Figure 3

SEM images of (a) 5, (b) 8, (c) 12 and (d) 15 wt\% Ery-CS NPs incorporated into 17\% CA solution, with their diameter histograms for each beside it. 
a
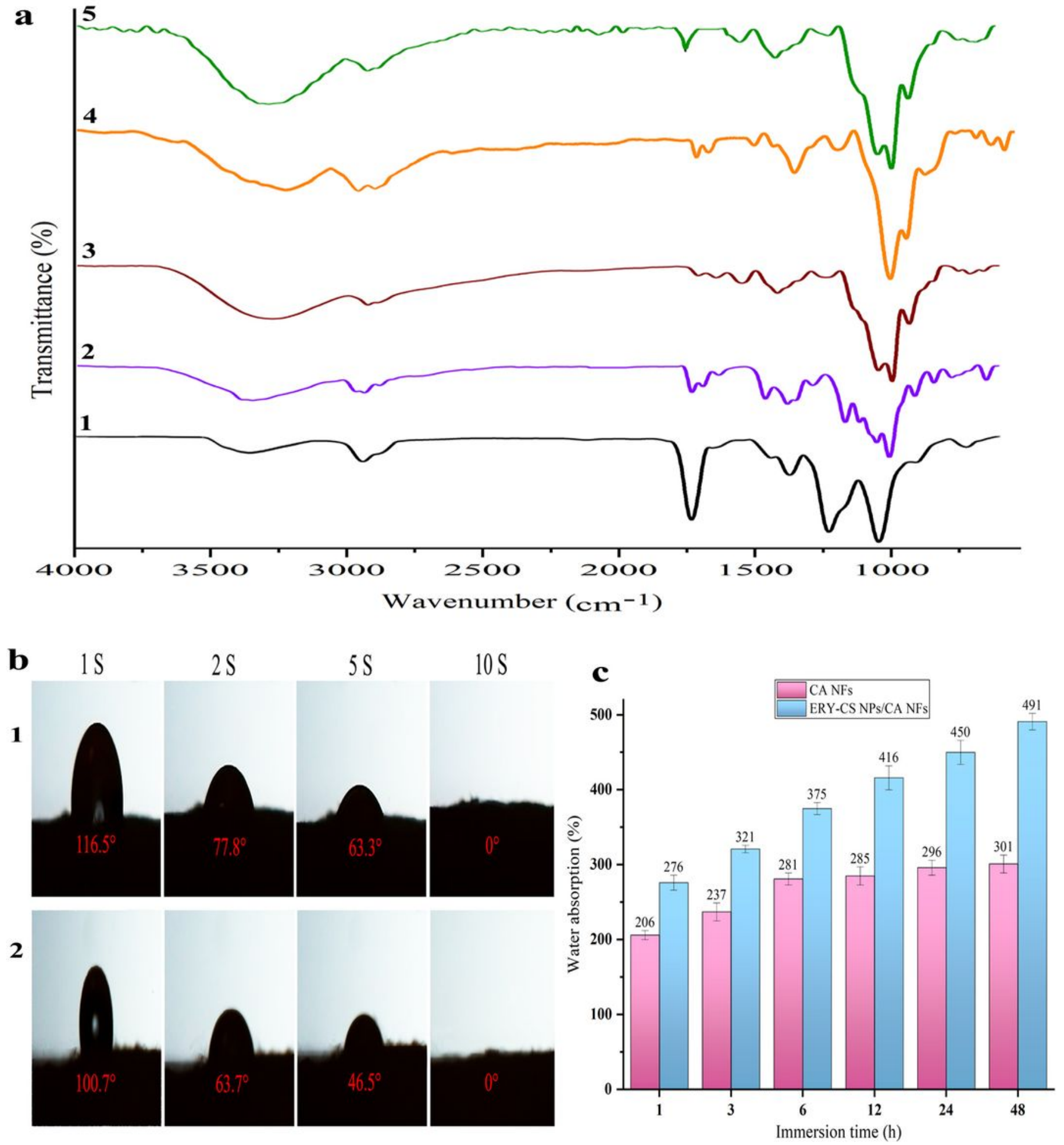

Figure 4

a) ATR-FTIR spectra of CA NFs (1), pure Ery (2), CS NPs (3), Ery-CS NPs (4) and Ery-CS NPs/CA NFs (5). b) Water contact-angle values for CA NFs (1) and Ery-CA NPs/CA NFs (2) at time 1 to $10 \mathrm{~s}$. c) The water absorption capacity of CA mats and Ery-CA NPs/CA mats at different immersion time. (Average of water absorption percentage is presented above the columns). 

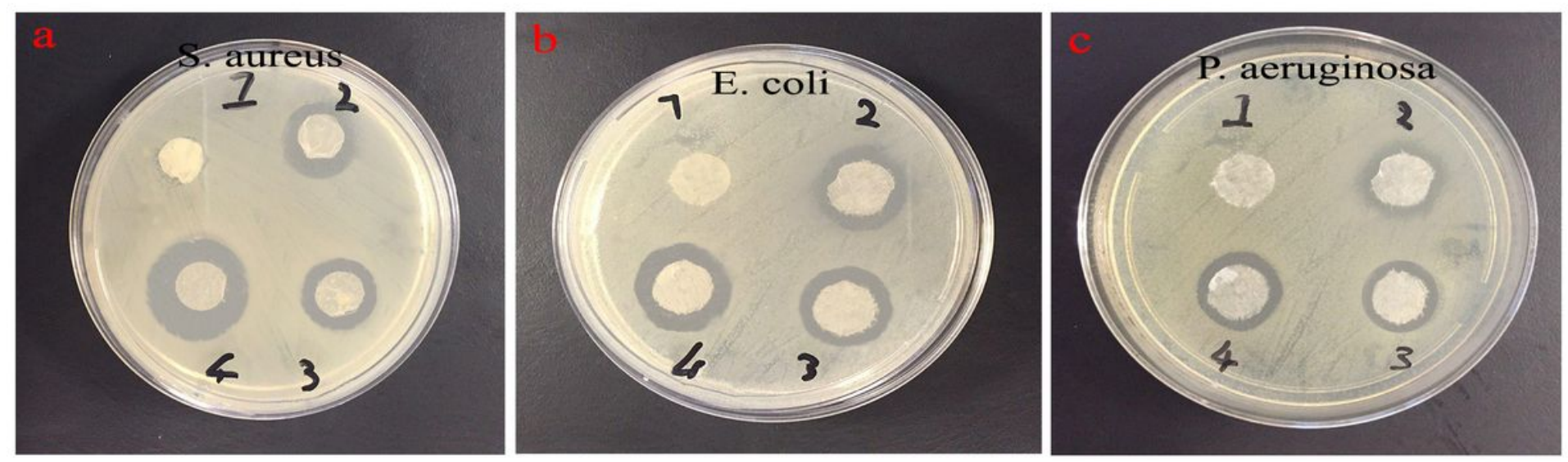

Figure 5

Bactericidal activity of the nanofibrous mats against Gram-positive: S. aureus (a), and Gram-negative: E. coli (b) and P. aeruginosa (c), respectively. CA, Ery/CA, CS NPs/CA and Ery-CS NPs/CA fiber mats were denoted as 1, 2, 3 and 4 respectively in the Petri plates.

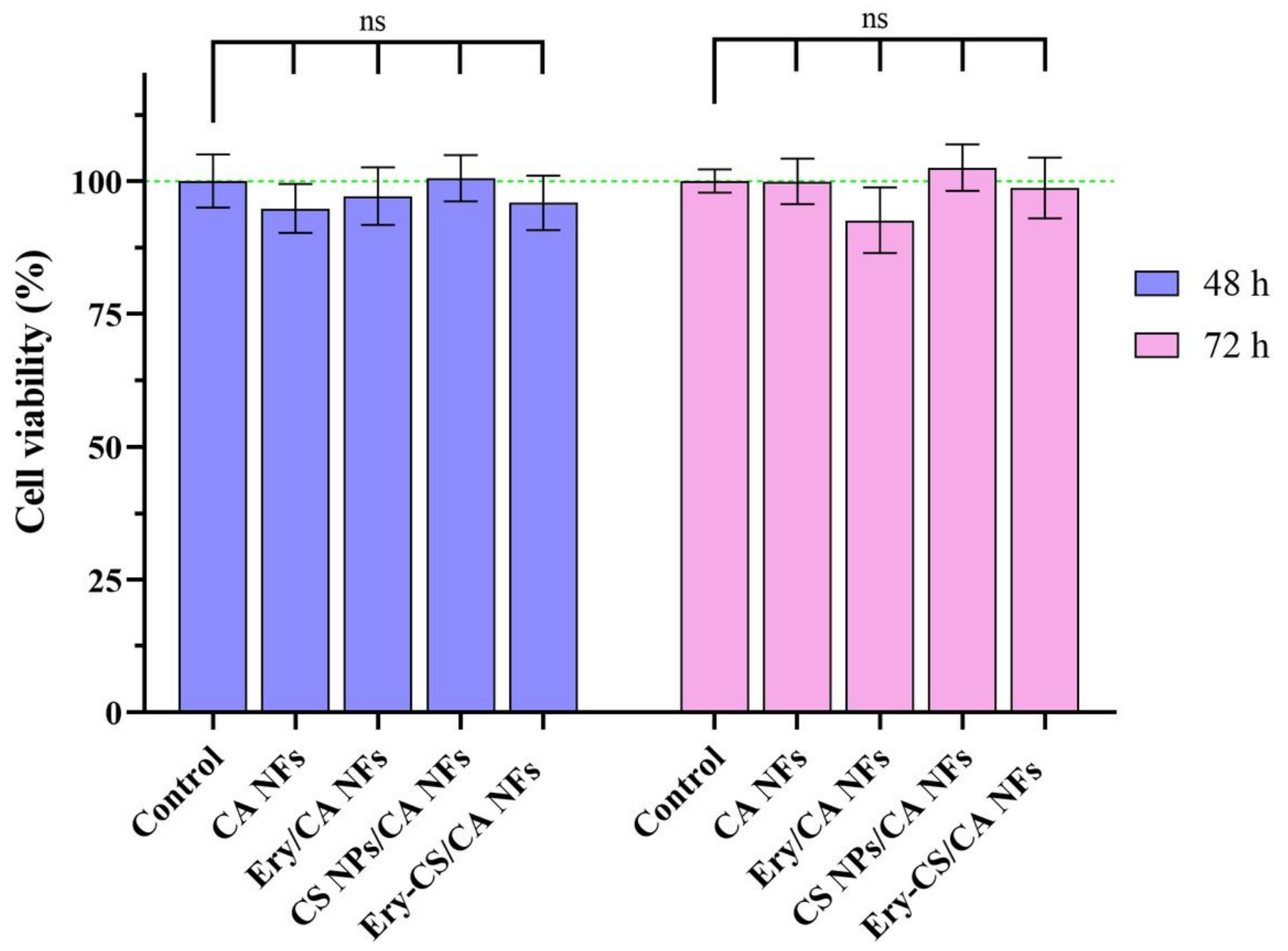


Figure 6

MTT cell growth measurement assay of the nanofibrous mats after 48 and $72 \mathrm{~h}$ incubation. The viability of control cells was set at $100 \%$.
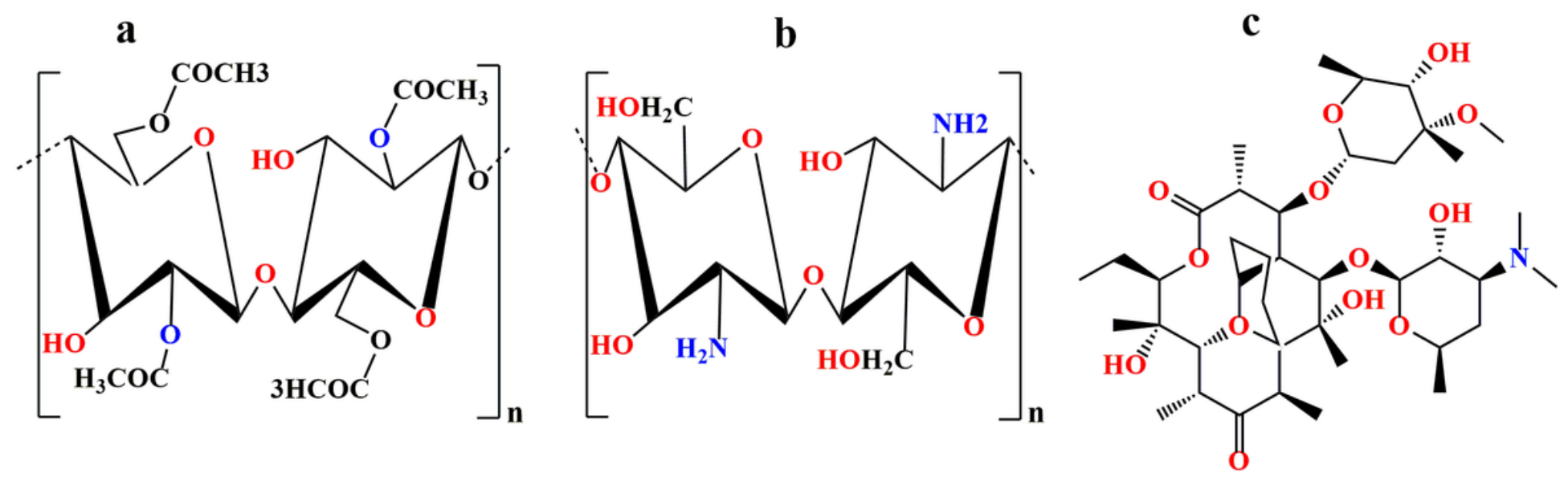

Figure 7

Scheme 1. Chemical structures of cellulose acetate (a), chitosan (b) and erythromycin (c). 